\title{
Research on the Impact of Human Activities on the Landscape Pattern in Jiuzhaigou Nature Reserve
}

\author{
Zhenhua Bing ${ }^{1}$, Jun Gao ${ }^{2}$ \\ ${ }^{1}$ Tourism and Food College, Shanghai Business School, Shanghai, 200234, China \\ ${ }^{2}$ School of Tourism, Shanghai Normal University, Shanghai, 200234, China
}

\begin{abstract}
Human activities and regional development will have a profound impact on the ecosystem and landscape structure[1]. There are many forms of human activities in the nature reserves, including tours, settlements, roads and so on. This paper selected three-phase sensing images of Jiuzhaigou Nature Reserve in 1997, 2004 and 2012 and analyzed landscape pattern. The study found that, Firstly, landscape pattern of Jiuzhaigou nature reserve was relatively stable, with balanced structure in different regions. Woodland landscape was the main landscape type in the nature reserve, its landscape dominance was obvious. Construction land area was the smallest, with lowest dominance. Human activities had little effect on the overall landscape pattern. Secondly, the landscape pattern of Jiuzhaigou Nature Reserve dynamic change analysis concluded that landscape pattern of Jiuzhaigou Nature Reserve between the different valleys was balanced, there was no obvious diversified and complicated or agglomeration areas. The Shuzheng valley, Rize valley and Zezhawa valley with concentrated human activities were no larger differences with other compared areas.
\end{abstract}

Keywords-landscape pattern; human activities; Jiuzhaigou nature reserve.

\section{INTRODUCTION}

Landscape pattern is the most important factor of landscape structure, which is a concrete manifestation of landscape heterogeneity. This determines the importance of the study of landscape spatial pattern. Some people think that the focus of modern landscape ecology is the study of spatial patterns and ecological processes of ecosystems on a larger spatial and temporal scale[2]. Quantitative description of the landscape pattern and analysis is the basic way to reveal the relationship between the landscape structure and landscape functions[3].

Landscape Ecology develop more rapidly from the 1980 s, landscape pattern study has shifted from focusing on the quantitative and qualitative description of spatial pattern to the various ecological processes, more and more scholars began to study the effect of landscape pattern changes to ecosystem[4], especially the effects of landscape pattern change on plant and animal habitats[5-7], and the influences of landscape pattern on the ecosystem function and service[8]. The domestic research includes landscape pattern research, environmental studies, environmental quality assessment and environmental monitoring, as well as social and environmental pollution and prevention and control. Among them, the latest research focused on wetlands [9], watershed [10], urban [11] as well as desertification landscape pattern evolution research [12].

In terms of research methods, most scholars adopt GIS tools for landscape pattern dynamic observation. The difference is that foreign scholars pay more attention to the landscape structure research of mountain and wetland, and domestic research is more concerned about the pattern evolution of urban space, watershed and other areas.

This paper selected landscape indices by the correlation exclusion, avoid repeating statements in the ecological significance; meanwhile, at the same time, selected the degree of fragmentation index, shape index and fractal index for reflecting changes in landscape structure and stability. Landscape pattern stability will reflect the impact of the human activities on nature reserves landscape pattern changes.

\section{RESEARCH AREA AND METHOD}

\section{A. Study area}

Jiuzhaigou Nature Reserve in Sichuan Aba Tibetan and Qiang Autonomous Prefecture, with a total area of 720 square kilometers. Jiuzhaigou was set for National Nature Reserve in 1978. Jiuzhaigou proposed to reduce construction land and arable land and remain accommodation in 1997. Jiuzhaigou had fully stopped farming and livestock, removal of accommodation facilities, and began to develop eco-tourism by 2004 . Jiuzhaigou was prohibited to build any artificial construction, with three sightseeing valleys, in addition to open up a new ecotourism valley in 2012 .

\section{B. Research method}

This paper used three remote sensing images in 1997、 2004 and 2012, shooting time was in August 1997, July 2004 and February 2012 respectively, with a resolution of each $(25 * 25 \mathrm{~m} \backslash 4.4 * 4.4 \mathrm{~m} \backslash 2.1 * 2.1 \mathrm{~m})$, analysing the dynamic variation of landscape pattern of the nature reserve at different times. Different remote sensing images were taken in different seasons, such as snow and ice were cover the image areas, inevitably had an impact on an area equivalent. The pre-processing of remote sensing image and landscape classification were used ENVI4.8 and ARCgis 10.0 software to operate. 
According to the second national land survey of the use of land-use classification standards, combined with the 1:50000 land use classification map of Jiuzhaigou nature reserve in 2006, the landscape types were divided into farmland forest, woodland, shrub, grassland, snow or bare rock, construction land, water, a total of seven categories. Through ENVI4.8 unsupervised classification, supervised classification and Arcgis10.0 artificial method to finish remote sensing image interpretation.

TABLE I. BASIS OF INFORMATION OF REMOTE SENSING IMAGES

\begin{tabular}{|c|c|c|c|c|}
\hline Remote Sensing & Satellite payload & Wave band & $\begin{array}{l}\text { Wavelength / spectral } \\
\text { range (Micron } \mu \mathrm{m})\end{array}$ & $\begin{array}{l}\text { Absolute radiometric } \\
\text { calibration coefficients gain }\end{array}$ \\
\hline & \multirow{7}{*}{ Landsat TM5 } & Band-1 & $0.45-0.52$ & - \\
\hline & & Band-2 & $0.52-0.60$ & - \\
\hline & & Band-3 & $0.63-0.69$ & - \\
\hline 1997、 & & Band-4 & $0.76-0.90$ & - \\
\hline \multirow[t]{4}{*}{2004} & & Band-5 & $1.55-1.75$ & - \\
\hline & & Band-6 & $10.4-12.50$ & - \\
\hline & & Band-7 & $2.08-2.35$ & - \\
\hline & \multirow[t]{4}{*}{ III multispectral imaging (ZY-3) } & Band-1 & $0.45-0.52$ & 0.2525 \\
\hline \multirow[t]{3}{*}{2012} & & Band-2 & $0.52-0.59$ & 0.2253 \\
\hline & & Band-3 & $0.63-0.69$ & 0.1791 \\
\hline & & Band-4 & $0.77-0.89$ & 0.1942 \\
\hline
\end{tabular}

Source: International Science Data Services Platform Website
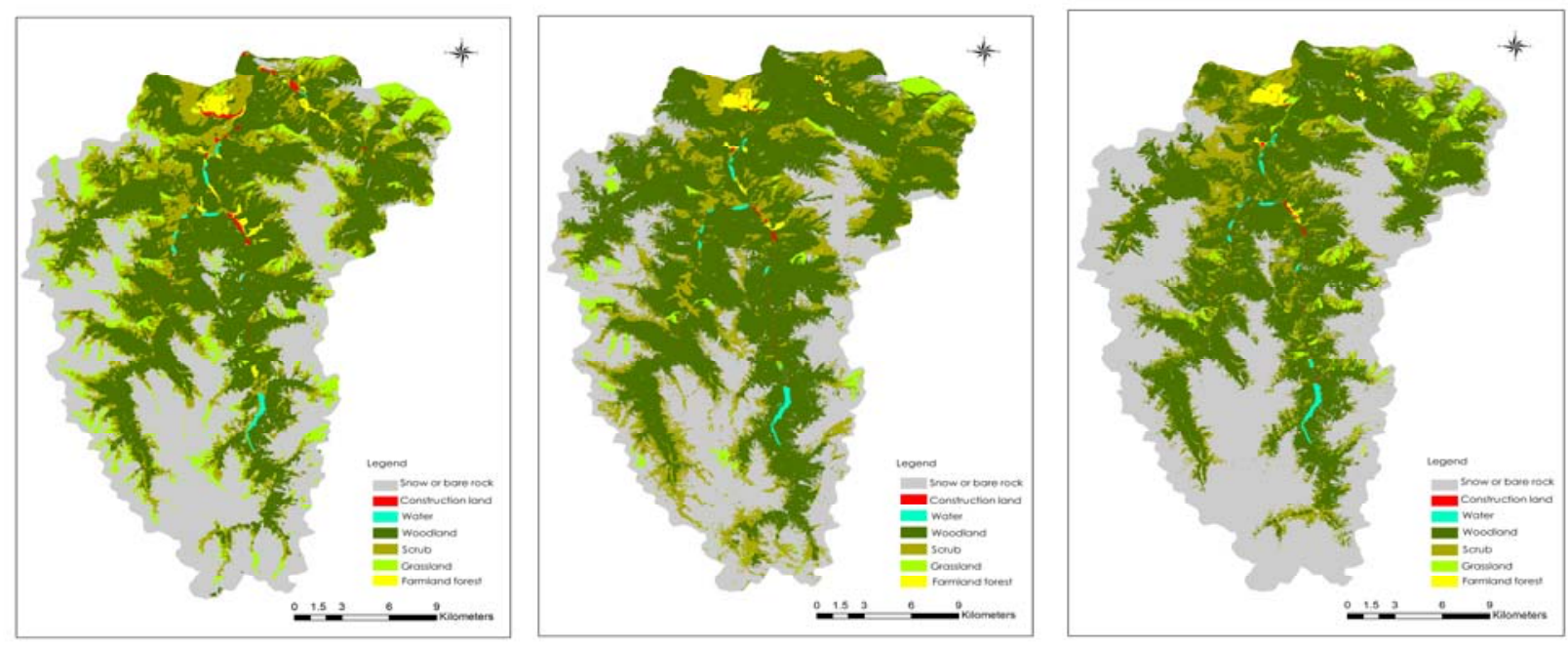

Figure 1. Land use classification map in 1997, 2004 and 2012

\section{Select size and index}

Fragstats 4.1 is used for the effect of particle size analysis and landscape index options. Upon analysis, the best scale selection of landscape pattern was $50 \mathrm{~m}$ in 1997 , $30 \mathrm{~m}$ in 2004 and $20 \mathrm{~m}$ in 2012.

In order to ensure that the selected indicators of scientific and non-relevance, this paper screened by landscape indices relevance. Landscape pattern based on different indices correlation and analysis requirements of this article, select the area index (CA / TA) and the largest patch index (LPI) the area to measure density and area, select the shape index (LSI), mean patch fractal dimension index (FRAC MN) and mean shape index (SHAPE MN) to measure the shape, select the polymerization index (AI) and patch density (PD) to measure degree of dispersion, select the Shannon's diversity index (SHDI) and evenness index (SHEI) to measure diversity.

\section{ANALYSIS AND RESULTS}

\section{A. Landscape pattern analysis}

This paper use the landscape pattern analysis software Fragstats4.1 and related statistical analysis tools to analyze three-phase landscape pattern of Jiuzhaigou Nature Reserve in 1997, 2004 and 2012 and comparative analyze the differences between different valleys and zones.

From the view of landscape patch density, the highest density was 41.64 in 2012, followed by the year 2004 of 18.56. The largest patch index was up to 47.44 in 2004 , 
followed by the 2012. Concentration degree was little difference between three-phase landscape patches of
Jiuzhaigou, it was slightly higher in 2012, as 90.92, 2004 and 1997 were 90.09 and 87.28.

TABLE II. LANDSCAPE PATCHES IN THE IMAGE CATEGORY INDEX IN 1997, 2004 AND 2012

\begin{tabular}{|c|c|c|c|c|c|c|c|}
\hline & PD & LPI & SHAPE_MN & FRAC_MN & SHDI & SHEI & AI \\
\hline 2012 & 41.64 & 37.04 & 1.147 & 1.033 & 1.129 & 0.580 & 90.92 \\
\hline 2004 & 18.56 & 47.44 & 1.134 & 1.026 & 1.156 & 0.594 & 90.09 \\
\hline 1997 & 8.61 & 22.90 & 1.179 & 1.029 & 1.314 & 0.675 & 87.28 \\
\hline
\end{tabular}

The analysis results show that the three-phase pattern of Jiuzhaigou nature reserve was more stable. Woodland landscape was the main landscape type in the nature reserve, its landscape dominance was obvious. Construction land area was the smallest, with lowest dominance.

\section{B. Comparative analysis of landscape pattern of different valleys}

Jiuzhaigou Nature Reserve was divided into Shuzheng valley, Rize valley, Zezhawa valley, Zharu valley, Danzu valley, Zangmalongli valley and Pujilongli valley. The Shuzheng valley, Rize valley and Zezhawa valley had been carried out for tourism, the Zharu valley's tourist accommodation was still few, the other three valleys belonged to undeveloped area, without settlements.

The Rize valley's landscape density was greatest, was 49.01 in 2012. About the largest patch index, Pujilongli valley landscape dominance was most obvious in 1997 and 2012, the index values were first in the different valleys, namely 65.24 and 81.28; landscape dominance of Shuzheng valley was obviously, with the index value of 67.19 in 2004.

Average shape index and mean patch fractal dimension index, the index value for each valley was insignificant. Mean patch fractal dimension index tended to 1 , indicating that patch shape was not complicated.

Comparison of landscape diversity, landscape diversity index of Zharu valley was 1.158 in 2012, ranked first. The landscape diversity index of Zangmalongli valley and Pujilongli valley with ewer human activities were the lowest.

Landscape evenness index of Danzu valley, Zangmalongli valley and Pujilongli valley with no tourism development were higher than other areas. Landscape evenness index of Danzu valley was 0.671, was the highest uniformity of nature reserve.
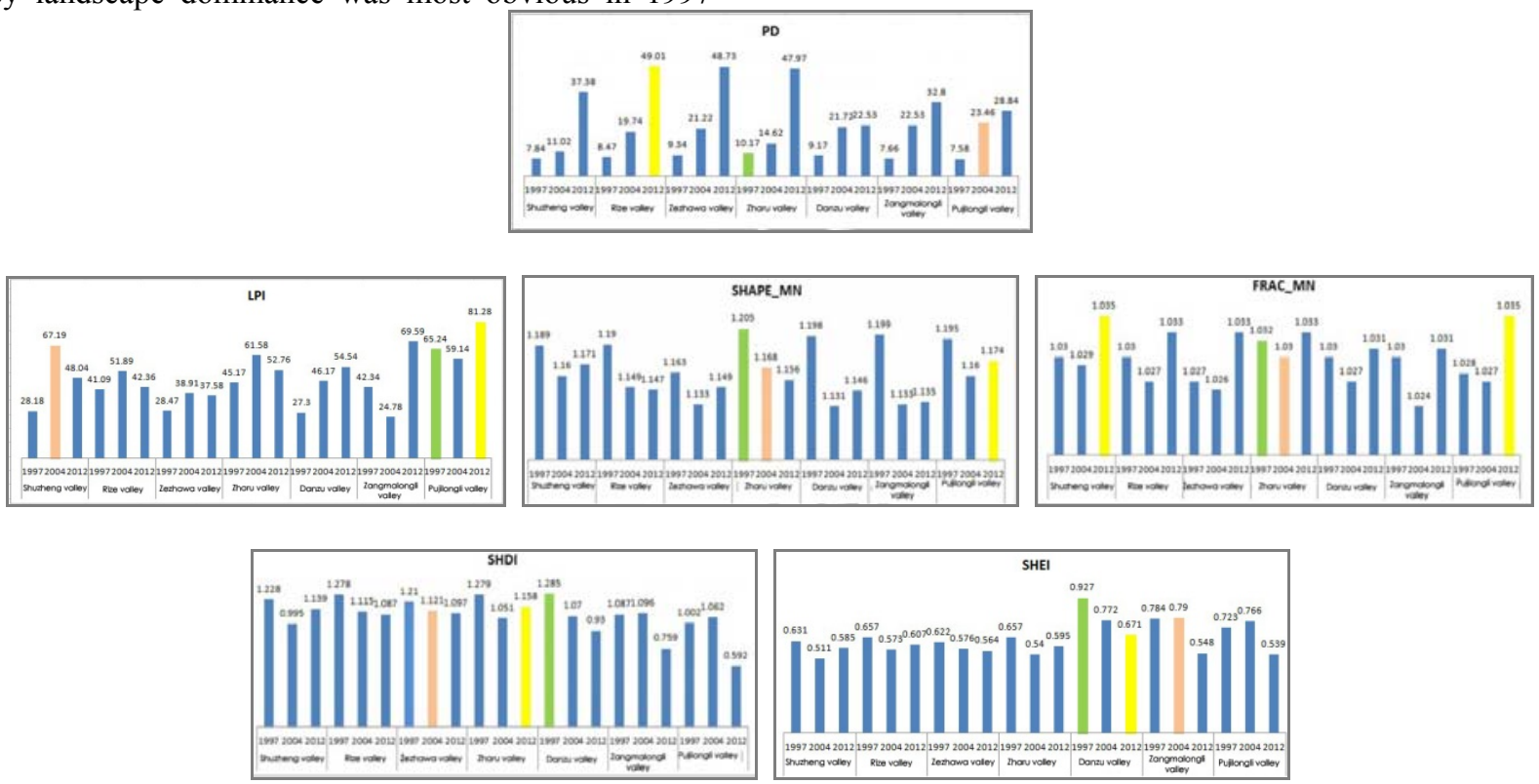

Figure 2. Nature Reserve Landscape Index Comparison Chart 


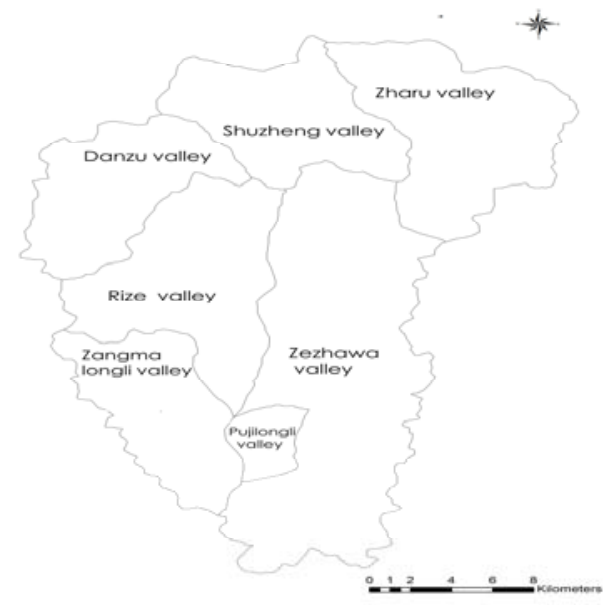

Figure 3. Different valleys of Jiuzhaigou Nature Reserve (Left)

\section{Comparative analysis of landscape pattern of different zones}

Jiuzhaigou nature reserve was divided into core zone, buffer zone and experimental zone three spheres. The human activity of experimental area was most intensive, with the main production and life of residents and tourism activities; core area was the focus of the protected area of nature reserves, there was no development of tourism activities; buffer area was the area located between the core area and the experimental zone.

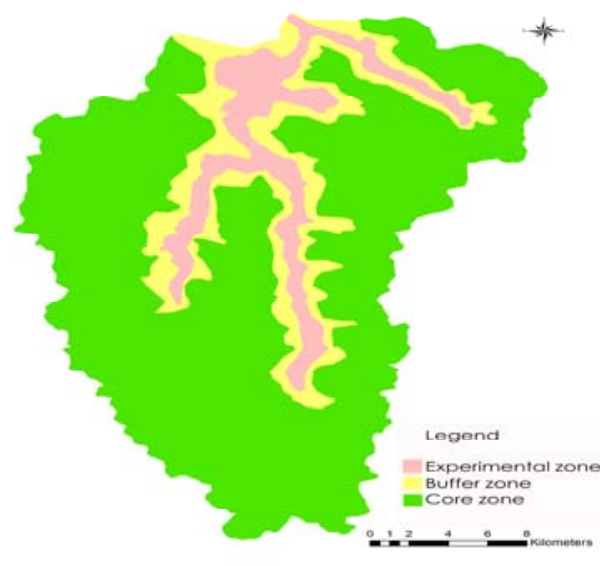

Figure 4. Different spheres of Jiuzhaigou Nature Reserve (Right)

Landscape diversity of experimental zone was the most significant, diversity indices were 1.25 in 1997 and 1.02 in 2012. The landscape evenness indices of the core area were highest in 1997, 2004 and 2012.

Overall, distributed landscape of the core zone with key protection was most evenly, landscape dominance and concentration were the more obviously; experimental zone and buffer zone with intensive human activities, landscape density increased significantly, landscape density distribution were 55.52 and 56.83 in 2012.

TABLE III. CHANGES IN DIFFERENT SPHERES OF LANDSCAPE INDICES NATURE RESERVE

\begin{tabular}{|c|c|c|c|c|c|c|c|c|}
\hline & & PD & LPI & SHAPE_MN & FRAC_MN & SHDI & SHEI & AI \\
\hline \multirow[t]{3}{*}{1997} & experimental zone & 11.03 & 21.28 & 1.222 & 1.034 & 1.25 & 0.64 & 83.66 \\
\hline & buffer zone & 11.04 & 8.09 & 1.201 & 1.031 & 0.91 & 0.47 & 84.53 \\
\hline & core zone & 9.1 & 23.8 & 1.186 & 1.03 & 1.22 & 0.76 & 86.91 \\
\hline \multirow[t]{3}{*}{2004} & experimental zone & 13.83 & 43.43 & 1.188 & 1.032 & 0.95 & 0.49 & 90.38 \\
\hline & buffer zone & 13.75 & 13.24 & 1.193 & 1.033 & 0.6 & 0.34 & 90.88 \\
\hline & core zone & 21.19 & 18.73 & 1.139 & 1.026 & 1.13 & 0.82 & 89.01 \\
\hline \multirow[t]{3}{*}{2012} & experimental zone & 56.38 & 41.04 & 1.164 & 1.035 & 1.02 & 0.53 & 87.63 \\
\hline & buffer zone & 55.52 & 11.04 & 1.184 & 1.036 & 0.83 & 0.43 & 87.23 \\
\hline & core zone & 39.56 & 46.71 & 1.152 & 1.033 & 0.98 & 0.71 & 91.51 \\
\hline
\end{tabular}

\section{CONCLUSIONS}

This paper selected three-phase sensing images of Jiuzhaigou Nature Reserve in 1997, 2004 and 2012 and analyzed landscape pattern. The study found that:

Firstly, landscape pattern of Jiuzhaigou nature reserve was relatively stable, with balanced structure in different regions. Woodland landscape was the main landscape type in the nature reserve, its landscape dominance was obvious. Construction land area was the smallest, with lowest dominance. Human activities had little effect on the overall landscape pattern.

Secondly, the landscape pattern of Jiuzhaigou Nature Reserve dynamic change analysis concluded that landscape pattern of Jiuzhaigou Nature Reserve between the different valleys was balanced, there was no obvious diversified and complicated or agglomeration areas.

Thirdly, distributed landscape of the core zone with key protection was most evenly, landscape dominance and concentration were the more obviously; experimental zone and buffer zone with intensive human activities, landscape density increased significantly.

\section{V.ACKNOWLEDGEMENTS}

This paper was financially supported by the project of National Natural Science Foundation of China "Research on the evaluation and regulation mechanism of landscape response-value-service by the action of tourism 
development - in the case of Jiuzhaigou national reserve"(41271554).

\section{REFERENCES}

[1] Nagashima K, Sands R, Whyte A G D, et al. Regional landscape change as a consequence of plantation forestry expansion: an example in the Nelson region, New Zealand. Forest Ecology and Management, 163,pp.245-261, 2002.

[2] Forman R. Land mosaics, the ecology of landscapes and regions. Cambridge : Cambridge University Press, 1995

[3] Wu Jianguo. Landscape ecology concepts and theories. Chinese Journal of Ecology, 19(1),pp.42-52, 2000.

[4] Turner M G, Gardner R H, O'neill R V. Landscape ecology in theory and practice: pattern and process. Springer Verlag, 2001.

[5] Mörtberg U M. Resident bird species in urban forest remnants; landscape and habitat perspectives. Landscape Ecology, 16(3),pp. 193-203,2001.

[6] Young C H, Jarvis P J. Measuring urban habitat fragmentation: an example from the Black Country, UK. Landscape Ecology, 16(7),pp.643-658,2001.
[7] Olff H, Ritchie M E. Fragmented nature: consequences for biodiversity. Landscape and Urban Planning, 58(2),pp.83-92,2002.

[8] Chen S, Chen L, Liu Q, et al. Remote sensing and GIS-based integrated analysis of coastal changes and their environmental impacts in Lingding Bay, Pearl River Estuary, South China. Ocean \& Coastal Management, 48(1),pp. 65-83,2005.

[9] Li Xiuzhen, Xiao Duning, Hu Yuanman, Wang Xianli. Effect of Wetland Landscape Pattern on Nutrient Reduction in the L iaohe Delta. Acta Geographica Sinica, (1),pp.32-43, 2001.

[10] Hu Hebing, Liu Hongyu, Hao Jingfeng, An Jing. Influence of Spatial Difference on Water Quality in Jiuxiang River Watershed, Nanjing. Environmental Science, (37),pp.794-801, 2012.

[11] Huang Jucong, Zhao Xiaofeng, Qiu Quanyi.Analysis on spatiotemporal changes of urban thermal landscape pattern in the context of urbanisation: a case study of Xiamen City. Acta Ecologica Sinica, (2),pp.622-631,2012.

[12] Duan Hanchen, Wang tao, Xue Xian, Guo Jian, Wen Xing. Spatialtemporal Evolution of Aeolian Desertification and Landscape Pattern in Horqin Sandy Land:A Case Study of Naiman Banner in Inner Mongolia. Acta Geographica Sinica, (7), pp.917-928, 2012. 